\title{
Influence of Thermal Aging Parameters on the Characteristics of Aluminum Semi-Solid Alloys
}

\author{
Khaled Ahmed Ragab ${ }^{1,2, *}$, Mohamed Bouazara ${ }^{1}$ and Xiao Grant Chen ${ }^{1}$ \\ 1 Applied Sciences, University of Quebec, Chicoutimi, QC G7H2B1, Canada; mbouazar@uqac.ca (M.B.); \\ xgrant_chen@uqac.ca (X.G.C.) \\ 2 Department of Metallurgy, Faculty of Engineering, Cairo University, Giza 12613, Egypt \\ * Correspondence: Khaled.ragab@uqac.ca; Tel.: +1-418-545-5011 (ext. 2501)
}

Received: 10 September 2018; Accepted: 20 September 2018; Published: 23 September 2018

\begin{abstract}
The current study aimed at analyzing the response of semisolid A357 aluminum alloys to unconventional thermal treatment cycles of $\mathrm{T} 4 / \mathrm{T} 6 / \mathrm{T} 7$ conditions. The mechanical, electrical, and microstructural characterizations of such semisolid alloys were investigated. The microstructure evolutions of Fe-intermetallic phases and strengthening precipitates were characterized using scanning electron microscopy (SEM) and transmission electron microscopy (TEM), respectively. The mechanical failure of such semi solid A357 aluminum alloys, used for suspension automotive parts, is mostly related to cracking issues which start from the surface due to hardness problems and propagate due to severe load variations. For these reasons, the multiple thermal aging cycles, in this study, are applied to enhance the mechanical properties and to have compromised values compared to those obtained by standard thermal treatments. The results obtained in this work indicate that the heat treatment of this alloy can be optimized. The results showed that the optimum characteristics of A357 semisolid alloys were obtained by applying thermal under-aging cycle, interrupted thermal aging cycles and a T7/T6 two steps aging treatment condition. The electrical conductivity and electron microscopy were applied in this study to analyze the characteristics of hardening phases formed due to different aging cycles applied to the alloys investigated.
\end{abstract}

Keywords: multiple thermal aging; mechanical properties; electrical conductivity; aluminum semi solid alloys; SEM; TEM

\section{Introduction}

Aluminum A357 semisolid alloys are considered to be excellent candidate materials for automotive engineering applications, especially of mechanical parts as suspension control arm. The microstructure and mechanical properties which are attainable in these alloys are known to be strongly influenced by solidification characteristics and heat treatment parameters. The semi-solid materials, SSM, produced by Swirled Equilibrium Enthalpy Device casting technique, SEED, is an efficient technology that offers several advantages over liquid and solid processing. The semisolid casting process improves the quality of A357 aluminum alloys by inducing qualitative casting with low shrinkage problems and beneficial microstructural characteristics. This casting technique, as well as the solution heat treatment process, plays a positive role in modifying the morphology of forming spheroid Si phases and fragmented iron intermetallic phases [1-4]. Due to the well-known characteristics of A357 semi solid alloys, they are used in fabrication of automotive parts, i.e., suspension control arm. The most common problems in these parts are mostly related to mechanical failure issues that may be affected by the surface quality due to hardness problems and by the strength and ductility of such alloys. The thermal treatment parameters, temperatures, and times have a significant effect on enhancing the performance of the alloys investigated $[4,5]$. 
The thermal treatment is considered to be the most important operation in the final fabrication process in the automotive industry to obtain the best combination of strength and ductility to make the metal better suited, structurally and physically, for specific applications. Traditional heat treatment procedures use continuous steps of the solution heat treating and continuous aging stages of a standard T6 or T7 heat treatment process. The standard T6 and T7 tempers have a specific sequence of steps starting with solution heat treatment and water quenching, and ending by the artificial thermal aging of different temperatures and times. The thermal aging treatment increases the strength at the expense of ductility depending on specific parameters. The aging temperature and time are the main parameters controlling the characteristics of the phases precipitated during aging treatment as well as the performance of these alloys [6-8]. Another study [8] using SEM microscopy showed that the solution heat treatment parameters, mainly temperature and times, have a significant effect on the morphology of Si and Fe intermetallic phases. The solution heat treatment enhances the ultimate tensile strength and ductility by dissolving most of the hardening soluble elements in the matrix, while thermal aging enhances the yield strength of Al-Si-Mg semi solid alloys at the expense of ductility. The T7 over aging treatment aims at reducing residual stress while increasing the performance of the alloy. The standard T6 and T7 tempers accelerate the aging rate by heat treating the product at higher temperatures of 150 to $230^{\circ} \mathrm{C}$, respectively, for specific times ranging from four to $10 \mathrm{~h}$. The main strengthening phases formed out of solid solution of Al-Si-M alloys are known as Nano-sized precipitates of $\beta-\mathrm{Mg}_{2} \mathrm{Si}$ phases identified using transmission, TEM, and electron microscopy. The Al-Si-Mg semi solid alloys may be naturally aged at room temperature, namely $\mathrm{T} 4$ temper, for long times which are effective when ranging from $12 \mathrm{~h}$ to $72 \mathrm{~h}$. The longer the natural aging stage, the more adversely affected the mechanical properties will be [9-11]. The maximum hardening response occurs when an alloy microstructure contains a combination of GP zones and well-dispersed semi-coherent precipitates. Greater hardening is possible provided an increase in the uniform dispersion of one or more of these phases is attained. This is possible with the use of multiple thermal aging treatments $[12,13]$. The transmission electron microscopy, TEM, research provides information about the crystal structure, size, shape and distribution of the precipitates that are necessary parameters to understand precipitation hardening. One of the disadvantages of TEM studies is that the volume that can be analyzed per sample is small, around $10^{-20}-10^{-18} \mathrm{~m}^{3}[14,15]$. Moreover, the electrical conductivity measurements may have been successfully used in the evaluation of strengthening phases' evolution due to applying of natural and artificial aging treatments $[15,16]$. The present study was conducted to provide a better understanding of the effects of multiple and interrupted thermal aging on the electrical, microstructural, and mechanical characteristics of A357 aluminum semi solid alloys.

\section{Materials and Methods}

The materials were prepared using the SEED semi-solid casting process from A357 aluminum alloy billets (Al-7\%Si- $0.6 \% \mathrm{Mg}-0.1 \% \mathrm{Fe}$ ). The alloys, received in the form of ingots, were melted in a silicon carbide crucible of 150-kg capacity, using an electric resistance furnace (Pyradia, Saint-Hubert, QC, Canada). The molten metal of the desired composition is transferred to a vessel whose thermal mass is sufficient to cool the melt. The vessel and its contents are swirled at $200 \mathrm{RPM}$, where the swirled enthalpy equilibration device process involves two main steps, at first, the heat is extracted to achieve the desired liquid-solid mixture, and then excessive liquid is drained to produce a self-supporting semisolid slug that is formed under pressure. The principal is based on achieving rapid thermal equilibrium between the metallic container and the bulk of the metal by proper process parameter selection such as pouring temperature, eccentric mechanical stirring, and drainage of a portion of eutectic liquid. The SEED process is coupled with a high pressure die casting (HPDC) press to produce cutting standard samples of A357 semi-solid alloys of suspension control arm, used for material characterization, mainly Vickers-micro hardness, electrical conductivity measurements, tensile properties, and microstructure evolution using TEM and SEM microscopy. 
Heat treatment was applied using several heat treatment cycles, as shown in Table 1 . The heat treatment process was carried out in an electric resistance furnace with a maximum temperature deviation of less than $1^{\circ} \mathrm{C}$. Table 1 indicates the heat treatment cycles applied on the samples of alloys investigated. The samples are initially subjected to two steps of solution heat treatment process in an electric resistance furnace to the isothermal holding temperatures of $470{ }^{\circ} \mathrm{C}$ for $1 \mathrm{~h}$ and of $540{ }^{\circ} \mathrm{C}$ for $5 \mathrm{~h}$. The two steps of solution heat treatment process is to avoid the incipient melting of strengthened $\mathrm{Mg}_{2} \mathrm{Si}$ phases with complete dissolution in the aluminum matrix while trying to dissolve and/or fragment the Fe intermetallic phases at higher temperatures for longer times. The samples are subsequently quenched in water maintained at $60{ }^{\circ} \mathrm{C}$. The samples are then subjected to a natural ageing process in room temperature for $24 \mathrm{~h}$. Specific samples, of micro-hardness and electrical conductivity, were quenched directly into the aging media after solution heat treatment process for comparison. The direct quenching into the aging media was related to the hot air quenching media for all thermal aging cycles investigated. Thermal aging cycles are applied regarding Table 1 . The thermal aging cycles in this work were divided into three categories, mainly T6/T7 aging treatment (A cycles), T7/T6 aging treatment (B cycles), and T6/T4/T7 interrupted aging treatment (C cycles) for specific times. The application of multi-temperature aging treatments aims at producing a compromise of strength levels comparable to those obtained from a T6 standard temper, yet with increased ductility, equal to or greater than that attained from a T7 temper. The aging treatment is applied to precipitate an excess amount of $\mathrm{Mg}$ and $\mathrm{Si}$ out of the supersaturated solid solution in the form of hardening phases containing $\mathrm{Mg}$ and Si. The decomposition of the supersaturated solid solution may involve the formation of independent clusters of Si and $\mathrm{Mg}$, followed by co-clusters of both Si and $\mathrm{Mg}$, coherent needlelike GP zones, coherent needle-shaped $\beta^{\prime \prime}$, coherent rod-shaped $\beta^{\prime \prime}$, and the incoherent plate-shaped $\beta-\mathrm{Mg}_{2} \mathrm{Si}$ phase [15-17].

Table 1. Multiple thermal aging cycles employed for A357-SSM alloys.

\begin{tabular}{|c|c|c|c|c|c|}
\hline \multicolumn{6}{|c|}{ Heat Treatment Regimes } \\
\hline Aging Cycles ID & SHT * & Quench & Age 1 & Age 2 & Age 3 \\
\hline SHT & $\begin{array}{c}470{ }^{\circ} \mathrm{C}, 1 \mathrm{~h} \\
+ \\
540^{\circ} \mathrm{C}, 5 \mathrm{~h}\end{array}$ & $60^{\circ} \mathrm{C}$ water & - & - & - \\
\hline \multicolumn{6}{|c|}{ A: Multiple Aging cycles (T6/T7) } \\
\hline $\mathrm{WA}_{0}(\mathrm{~T} 6 / \mathrm{T} 7)$ & \multirow{5}{*}{\multicolumn{2}{|c|}{$\begin{array}{c}470{ }^{\circ} \mathrm{C}, 1 \mathrm{~h} \\
+ \\
540^{\circ} \mathrm{C}, 5 \mathrm{~h}\end{array}$}} & $150^{\circ} \mathrm{C}-2 \mathrm{~h}$ & $230^{\circ} \mathrm{C}-0 \mathrm{~h}$ & - \\
\hline $\mathrm{WA}_{1}(\mathrm{~T} 6 / \mathrm{T} 7)$ & & & $150^{\circ} \mathrm{C}-2 \mathrm{~h}$ & $230^{\circ} \mathrm{C}-1 \mathrm{~h}$ & - \\
\hline $\mathrm{WA}_{3}(\mathrm{~T} 6 / \mathrm{T} 7)$ & & & $150^{\circ} \mathrm{C}-2 \mathrm{~h}$ & $230^{\circ} \mathrm{C}-3 \mathrm{~h}$ & - \\
\hline $\mathrm{WA}_{5}(\mathrm{~T} 6 / \mathrm{T} 7)$ & & & $150^{\circ} \mathrm{C}-2 \mathrm{~h}$ & $230{ }^{\circ} \mathrm{C}-5 \mathrm{~h}$ & - \\
\hline $\mathrm{WA}_{8}(\mathrm{~T} 6 / \mathrm{T} 7)$ & & & $150^{\circ} \mathrm{C}-2 \mathrm{~h}$ & $230^{\circ} \mathrm{C}-8 \mathrm{~h}$ & - \\
\hline \multicolumn{6}{|c|}{ B: Multiple Aging cycles (T7/T6) } \\
\hline $\mathrm{WB}_{0}(\mathrm{~T} 7 / \mathrm{T} 6)$ & \multirow{5}{*}{\multicolumn{2}{|c|}{$\begin{array}{c}470{ }^{\circ} \mathrm{C}, 1 \mathrm{~h} \\
+ \\
540^{\circ} \mathrm{C}, 5 \mathrm{~h}\end{array}$}} & $230^{\circ} \mathrm{C}-2 \mathrm{~h}$ & $150^{\circ} \mathrm{C}-0 \mathrm{~h}$ & - \\
\hline $\mathrm{WB}_{1}(\mathrm{~T} 7 / \mathrm{T} 6)$ & & & $230^{\circ} \mathrm{C}-2 \mathrm{~h}$ & $150^{\circ} \mathrm{C}-1 \mathrm{~h}$ & - \\
\hline $\mathrm{WB}_{3}(\mathrm{~T} 7 / \mathrm{T} 6)$ & & & $230^{\circ} \mathrm{C}-2 \mathrm{~h}$ & $150^{\circ} \mathrm{C}-3 \mathrm{~h}$ & - \\
\hline $\mathrm{WB}_{5}(\mathrm{~T} 7 / \mathrm{T} 6)$ & & & $230^{\circ} \mathrm{C}-2 \mathrm{~h}$ & $150^{\circ} \mathrm{C}-5 \mathrm{~h}$ & - \\
\hline $\mathrm{WB}_{8}(\mathrm{~T} 7 / \mathrm{T} 6)$ & & & $230^{\circ} \mathrm{C}-2 \mathrm{~h}$ & $150^{\circ} \mathrm{C}-8 \mathrm{~h}$ & - \\
\hline \multicolumn{6}{|c|}{ C: Interrupted Aging cycles (T6/T4/T7) } \\
\hline $\mathrm{WC}_{1}(\mathrm{~T} 6 / \mathrm{T} 4 / \mathrm{T} 7)$ & \multirow{3}{*}{$\begin{array}{c}470{ }^{\circ} \mathrm{C}, 1 \mathrm{~h} \\
+ \\
540{ }^{\circ} \mathrm{C}, 5 \mathrm{~h}\end{array}$} & \multirow{3}{*}{$60^{\circ} \mathrm{C}$ water } & $150^{\circ} \mathrm{C}-1 \mathrm{~h}$ & $\begin{array}{c}190^{\circ} \mathrm{C}-1 \mathrm{~h} \\
+ \\
25^{\circ} \mathrm{C}-24 \mathrm{~h}\end{array}$ & $230^{\circ} \mathrm{C}-2 \mathrm{~h}$ \\
\hline $\mathrm{WC}_{2}(\mathrm{~T} 6 / \mathrm{T} 7 / \mathrm{T} 7)$ & & & $150^{\circ} \mathrm{C}-1 \mathrm{~h}$ & $190^{\circ} \mathrm{C}-1 \mathrm{~h}$ & $230^{\circ} \mathrm{C}-2 \mathrm{~h}$ \\
\hline $\mathrm{WC}_{3}(\mathrm{~T} 6 / \mathrm{T} 4 / \mathrm{T} 7)$ & & & $\begin{array}{c}150^{\circ} \mathrm{C}-3 \mathrm{~h} \\
+ \\
25^{\circ} \mathrm{C}-24 \mathrm{~h}\end{array}$ & $190^{\circ} \mathrm{C}-2 \mathrm{~h}$ & $230^{\circ} \mathrm{C}-1 \mathrm{~h}$ \\
\hline
\end{tabular}

* SHT: Solution Heat treatment. 
The tensile test bars were cutting from the control arm of A357 semi solid alloys according to the standard dimensions of sub-sized specimens ASTM-E8M; each with a gauge length of $25 \mathrm{~mm}$ and a width of $6 \mathrm{~mm}$. The heat-treated test bars, five samples for each thermal cycle condition, were pulled to fracture at room temperature at a strain rate of $1 \times 10^{-4} / \mathrm{s}$ using a Servo hydraulic MTS Mechanical Testing machine (Instron, Norwood, MA, USA). The tensile properties, mainly ultimate tensile strength (UTS), yield strength (YS), and elongation $\left(\% \mathrm{E}_{\mathrm{f}}\right)$ were determined per heat treatment cycle. Vickers hardness test (ASTM:E384) of the aged samples was carried out on a model HV-10B instrument (Instron, Norwood, MA, USA) under a load of $4.9 \mathrm{~N}$. The dimensions of the disc shaped specimens used for micro hardness measurements (Vickers hardness HV) are $15 \mathrm{~mm}$ diameter and $3 \mathrm{~mm}$ thickness. Each HV value is obtained from the average of at least 10 readings distributed over the whole surface of the specimen. The electrical conductivity was measured, with an SMP10 type conductivity meter, by the average of five readings for each thermal treatment cycle. Scanning electron microscopy (SEM, JSM-6480 LV, JEOL, Tokyo, Japan) was used to study the effect of semisolid casting and solution heat treatment on the characteristics of intermetallic phases, namely $\mathrm{Si}$ and Fe phases, of A357 alloys. Samples of A357 alloys were used to indicate the size and distribution of the $\mathrm{Mg}_{2} \mathrm{Si}$ strengthening phases relating to the different thermal aging parameters of specific multiple and interrupted thermal aging conditions, by means of TEM.

Metallographic specimens were cut and polished using standard procedures for scanning/transmission electron microscopy (TEM, JEM-2100, JEOL, Tokyo, Japan), SEM/TEM, and samples preparation. The TEM samples of thin foils, of $60 \mu \mathrm{m}$ thickness and $3 \mathrm{~mm}$ diameter, were prepared by grinding and electro-polishing using Twin-Jet device using nitric acid and methanol (EMS, 550D, Hatfield, PA, USA) at $-30^{\circ} \mathrm{C}$ with a current of $\sim 0.15 \mathrm{~A}$. Four TEM samples were prepared for the specific thermal aging cycles investigated.

\section{Results and Discussion}

\subsection{Electrical Conductivity and Micro-Hardness}

Figures 1 and 2 show the electrical conductivity and the micro hardness measurements of A357 aluminum semi solid alloys subjected to multiple thermal aging treatments using water quenching $\left(60^{\circ} \mathrm{C}\right)$ and direct quenching-aging media, respectively. The measurement of electrical conductivity may be considered to be an indirect technique to understand the nature and distribution of the precipitates in the heat-treated alloys. Regarding Figures 1 and 2, it is clearly observed that the electrical conductivity is responsive to the application of multiple aging cycles T6/T7 ( $A_{i}$ conditions) and T6/T7 ( $\mathrm{B}_{\mathrm{i}}$ conditions), compared to $\mathrm{A}_{0}$ and $\mathrm{B}_{0}$ conditions. This can be explained by the fact that the electrical conductivity is highly affected by the quantity of solute in the matrix $[16,17]$.

Regarding the electrical conductivity, it may be noted by that the values of solution heat-treated alloys (SHT) decreased slightly after applying T6 aging condition for $2 \mathrm{~h}$. The electrical conductivity values started to highly increase by directly following the T6 aging by T7 aging cycles, $A_{i}$ (T6/T7) conditions. The electrical conductivity measurements indicated a continuously increase as the duration times of applied $\mathrm{T} 7 \mathrm{~s}$ step aging increase until $8 \mathrm{~h}$ ( $\mathrm{A}_{1}$ to $\mathrm{A}_{8}$ conditions). In comparison, the electrical conductivity measurements returned to lower values with the application of low temperature aging (T6) cycle following higher temperature aging (T7) cycle and $\mathrm{B}_{\mathrm{i}}(\mathrm{T} 7 / \mathrm{T} 6)$ conditions. In addition, the electrical conductivity indicated a continuous decrease with the increase of the aging times of the applied T7 s step aging cycles until $8 \mathrm{~h}$ ( $\mathrm{B}_{1}$ to $\mathrm{B}_{8}$ conditions). The electrical conductivity measurements did not show a significant difference by the application of interrupted thermal aging cycles of $C_{i}$ conditions and/or by the application of direct quenching-aging media. It is well known that the addition of specific alloying elements into an aluminum matrix reduces its electrical conductivity. Hence, the alloy that is in a solid solution state shows the lowest value. The solution heat treatment process exhibits the lowest conductivity since the quenching process retains all the alloying elements in solid solution at room temperature. By the application of under aging treatment $\mathrm{A}_{0}$, the conductivity 
initially decreases further low due to the formation of closely spaced GP zones and semi coherent fine precipitates. As the ageing progresses at higher temperature for longer times $\left(\mathrm{A}_{1-8}\right)$, the precipitates coarsen due to the effect of diffusion. The formation of equilibrium and coarse incoherent precipitates at high temperature aging and/or long time leads to the loss of solutes in the matrix. In addition, formation of coarse precipitates, at the expense of interspacing, leads to the wide spacing between the precipitates. These two factors contribute to the increase of conductivity of A357/Al-Si-Mg alloys [15-18]. The reason for this discrepancy might be an additional contribution into the electron scattering of elastic strain fields, which normally exist near the GP zones coherently conjugated with a metal matrix. This assumption is well supported by the fact that the formation of semi coherent intermediate phase results in a significant increase in electrical conductivity values. Another reason contributing to the above discrepancy might be related to some diffraction effects, which normally accompanies scattering of electron waves and are likely to be maximally seen at a certain stage of the formation of ordered atomic structure in clusters $[19,20]$. Thus, the precipitate size and distributions in the alloy can be easily analyzed by just measuring electrical conductivity values.

Regarding the micro hardness measurements, it can be noted that the hardness values are significantly responsive to thermal aging cycles; the hardness increases with the application of T6 under aging condition after $2 \mathrm{~h}$, compared to solution heat treated alloys, SHT cycle. However, the application of multiple aging cycles of $\mathrm{T} 6 / \mathrm{T} 7-\mathrm{A}_{1,3,5,8}$ conditions leads to a significant decrease of hardness values compared to T6-under aging $\mathrm{A}_{0}$ thermal treatment conditions. This continuous decrease in the micro-hardness values is related to the effect of high temperature of applied T7 aging cycle as a second step which may lead to the coarsening of formed precipitates, mainly larger-wide spaced precipitates. It was noted that a significant re-increase of micro-hardness values by the application of multiple thermal aging cycles (T7/T6) of $\mathrm{B}_{1,3,5,8}$ conditions compared to the $\mathrm{T} 7$ over aging condition of $\mathrm{B} 0$ thermal cycle. The micro-hardness values increased continuously till $5 \mathrm{~h}$ of the T6 step aging; the values decreased after $8 \mathrm{~h}$ of thermal aging, as shown by $\mathrm{B}_{8}$ cycle in Figures 1 and 2 . In addition to under aging cycle $\mathrm{A}_{0}$ and multiple thermal aging $\mathrm{B}_{5}$ cycle, the application of interrupted thermal aging $\mathrm{C}_{3}$ cycles indicated an enhancement of micro-hardness values compared to solution heat treated samples (SHT). The re-increase of hardness values, after following the T7 aging directly with the T6 condition of $\mathrm{B}_{1,3,5}$ cycles, may be related to the formation of smaller size, semi coherent type, of $\mathrm{Mg}_{2} \mathrm{Si}$ precipitates. These semi coherent precipitates may be formed in the interspacing between the coherent precipitates that are previously formed after T7 over aging treatment. This may be confirmed by electrical conductivity measurements. As the spacing between particles and/or precipitate size increases, the alloy loses its strength properties due to dislocation bowing (over looping) mechanisms. The dislocation motion is no longer effectively blocked or resisted by the presence of coarse-widely spaced precipitates which is leading to the earlier yielding of the alloy. It is well known that particles of intermediate semi coherent phases mainly contribute to alloy hardening, while reorganisation of such intermediate phase precipitates into a stable phase results in lower strength characteristics, hardness in particular [19-21]. In addition, an obvious reverse relationship between the electrical conductivity and the micro hardness values is relating to the effect of different heat treatment cycles applied in this study. Other studies [21,22] have noticed that there is a non-linear correlation of electrical conductivity, hardness and strength for Aluminum alloys. It was also noted that the micro-hardness values were decreased by the application of direct quenching in the aging media compared to the water quenching media at $80{ }^{\circ} \mathrm{C}$. The direct quenching-aging media indicated a negative effect on the formation of $\mathrm{Mg}_{2} \mathrm{Si}$ precipitates. This was clearly indicated by the application of micro structure characterization, using SEM microscopy, indicated in this study. 


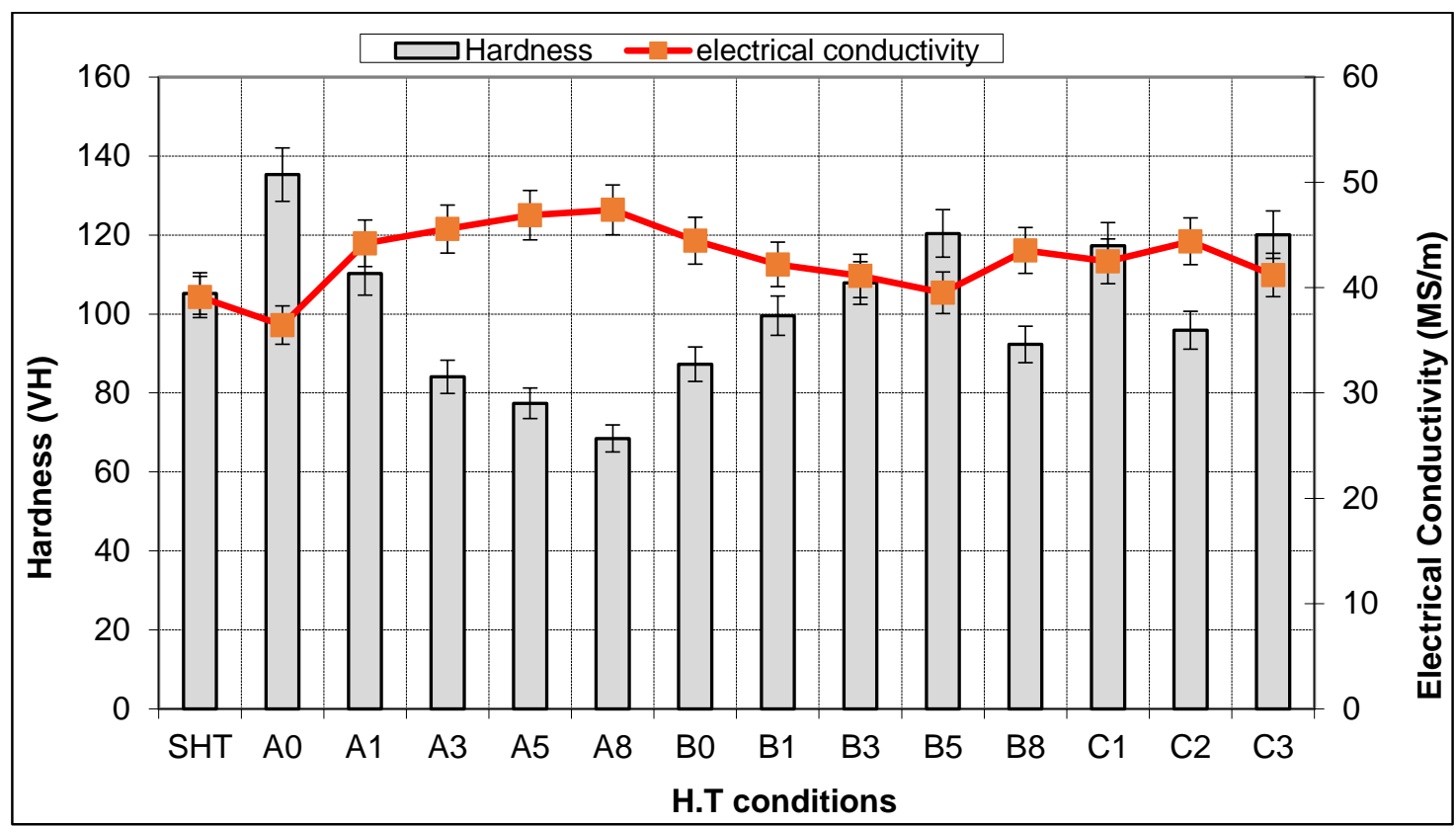

Figure 1. Hardness and electrical conductivity of water quenching A357-SSM heat treated using multiple thermal aging treatments.

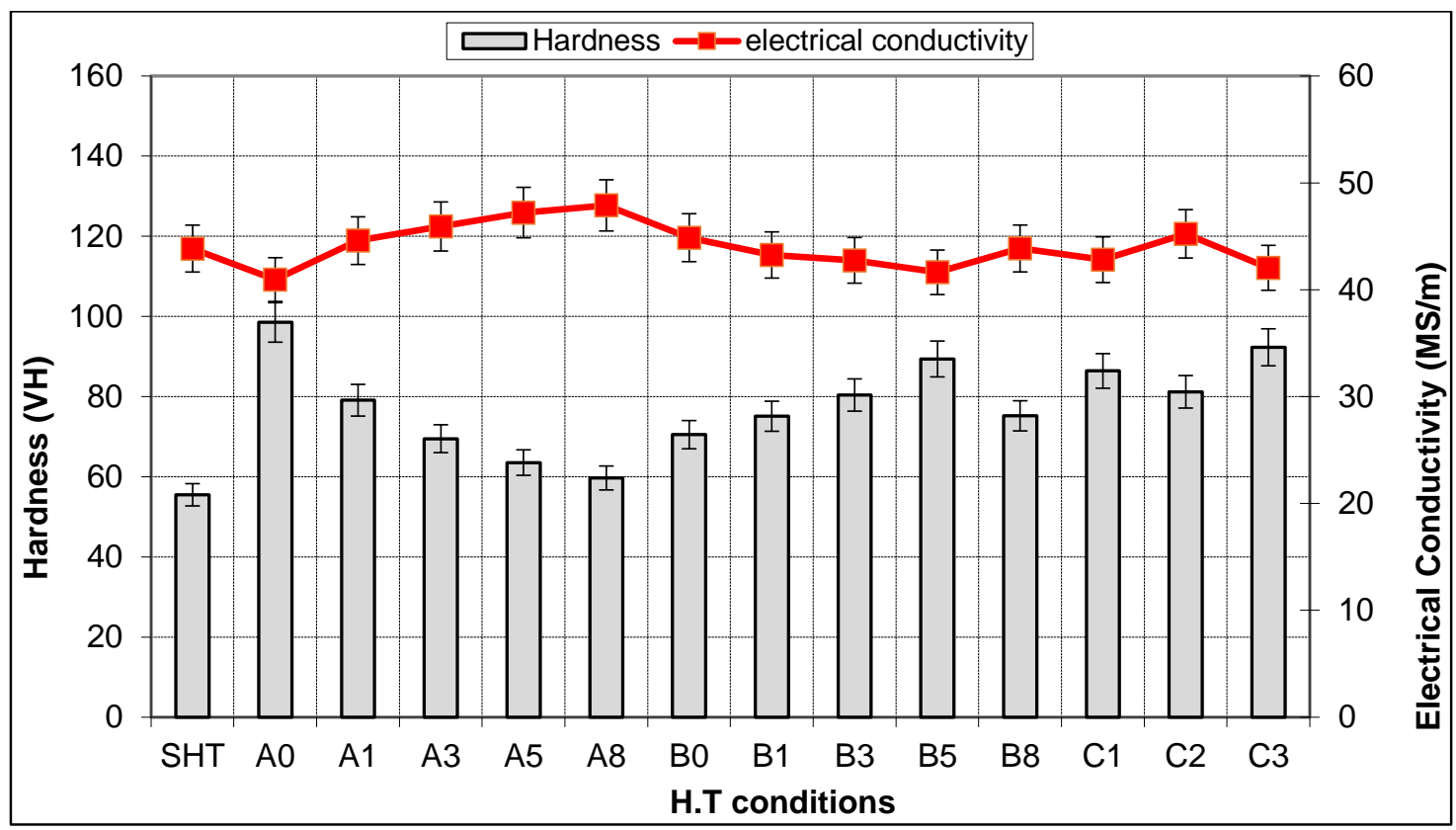

Figure 2. Hardness and electrical conductivity of direct hot air quenching-aging of A357-SSM heat treated using multiple thermal aging treatments.

\subsection{Tensile Properties}

Figures 3 and 4 indicate the tensile strength and elongation values, respectively, obtained by the application of multiple thermal aging cycles. From Figure 3, it is seen that the application of multiple $A_{1}-T 6 / T 7$ aging cycle, multiple $B_{5}-T 7 / T 6$ aging cycle and interrupted $C_{3}$ aging cycle, yields higher strength values than nearly all applied thermal aging cycles. The strength values obtained in this study are slightly lower than those obtained by applying T6 standard thermal treatment (316 MPa for UTS, $265 \mathrm{MPa}$ for YS), according to the literature in References [10-15]. However, the application of $\mathrm{A}_{1}$ (T6/T7) and $\mathrm{C}_{3}$ (T6/T4/T7) aging cycles indicated nearly all strength values (290 MPa for 
UTS, $260 \mathrm{MPa}$ for YS and $302 \mathrm{MPa}$ for UTS, and $288 \mathrm{MPa}$ for YS, respectively) to T6 standard aging. In addition, the application of multiple thermal aging treatments of $A_{i}$ cycles indicated an enhancement in the elongation results ( $8-10 \%$ for $A_{1,3,5,8}$ cycles and $15 \%$ for $A_{0}$ under raging cycle), compared to those obtained by standard T6 aging treatment (4-6\%) according to the literature in References [10-15], as shown by Figure 4 .

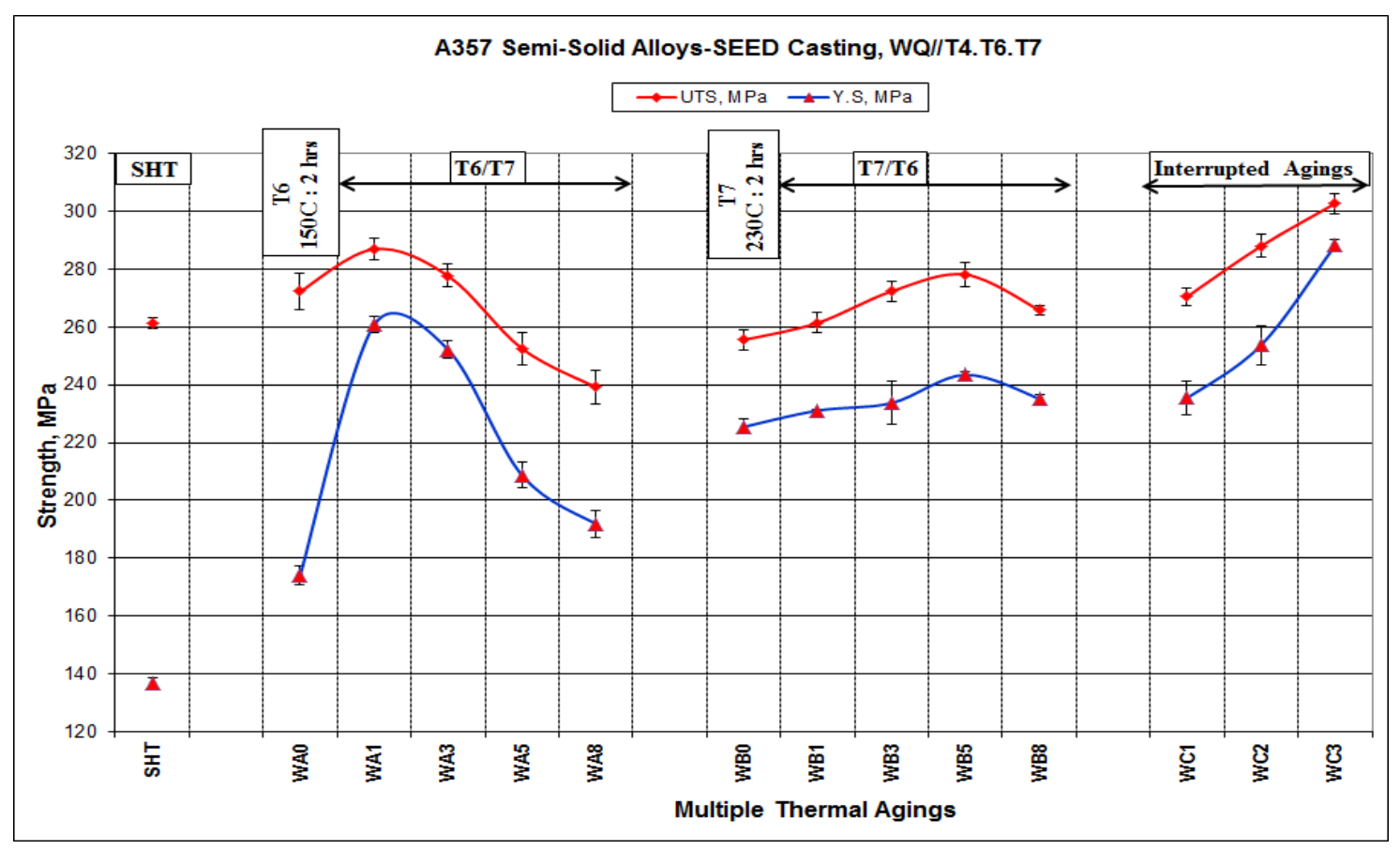

Figure 3. Tensile strength values of water quenching A357-SSM heat treated using multiple thermal aging treatments.

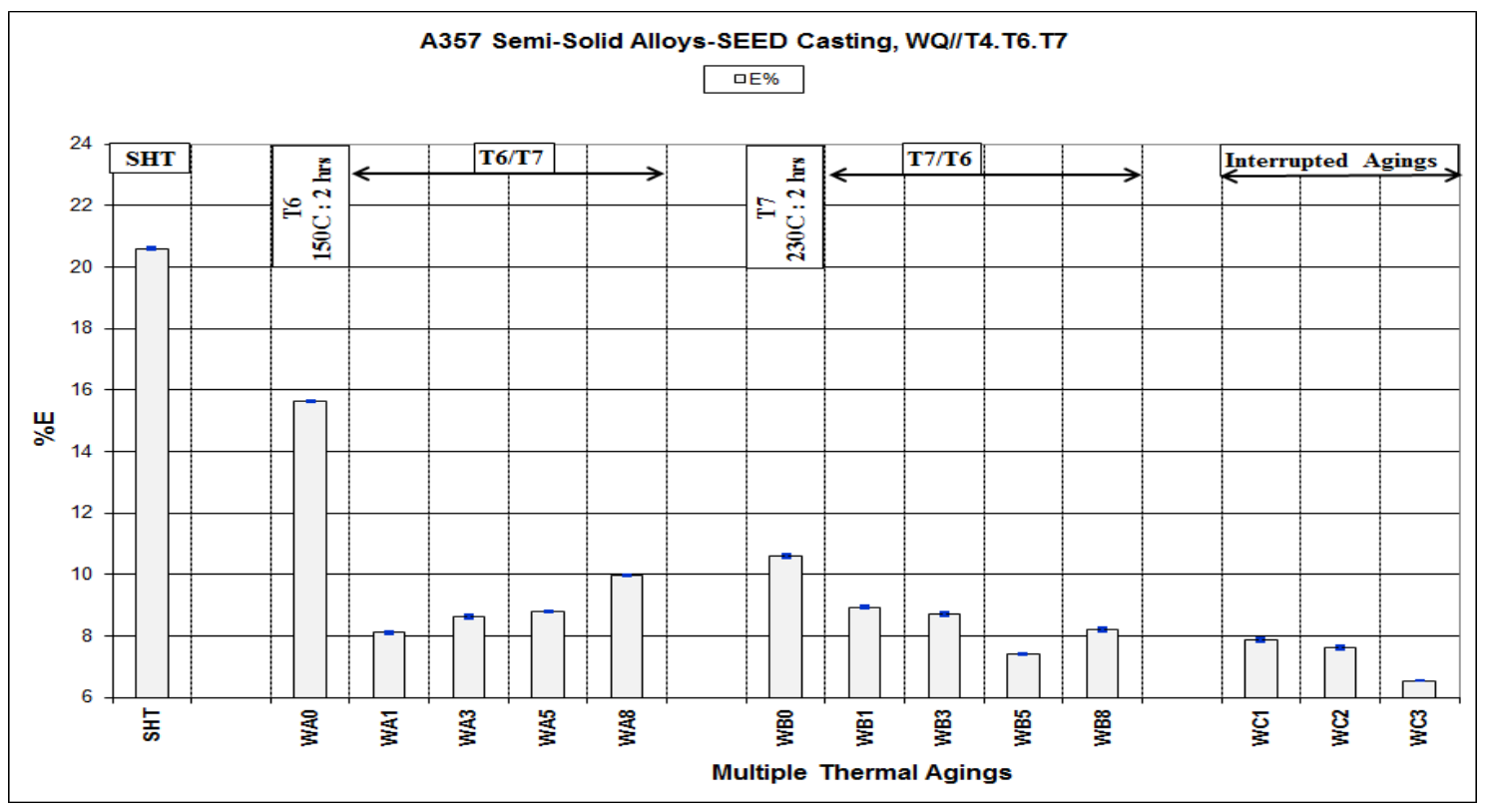

Figure 4. Average values of elongation (El \%) of water quenching A357-SSM heat treated using multiple thermal aging treatments.

The decrease in strength values of T6/T7 multiple thermal aging of $A_{1,3,5,8}$ cycles, compared to under aging $\mathrm{A}_{0}$ cycle, may be attributed to the increase in the precipitates size as well as the 
inter-particle spacing between precipitates, which makes dislocation bowing much easier [15-19]. The decrease in the strength of the 356 alloy, accompanying the over-aging, is related to the loss of the coherency strain surrounding the precipitates through the formation of incoherent, stable $\beta-\mathrm{Mg}_{2} \mathrm{Si}$ phases. In addition to the loss of coherency, the longer aging time at $230{ }^{\circ} \mathrm{C}$, second step aging results in the coarsening of the large precipitates at the expense of the small ones. This coarsening effect produces a lower density of the widely dispersed, coarse precipitates. These changes in the precipitates the features reduce the resistance to dislocation motion through the metal matrix and lead to a deformable soft matrix. On the other side, the T7/T6 multi-temperature aging of $\mathrm{B}_{1,3,5,8}$ cycles produce an increase in strength values by increasing the T6-s stage aging times, as compared to a $\mathrm{T} 7$ over aging $\mathrm{B}_{0}$ temper alone (i.e., with no subsequent $\mathrm{T} 6$ aging stage). At the temperature of the second aging stage $\left(150{ }^{\circ} \mathrm{C}\right)$, the T7-treated alloy microstructure may have been refined by the $\mathrm{T} 6$ treatment into a fine dispersion of semi-coherent clusters of $\mathrm{Mg}_{2} \mathrm{Si}$ strengthening phase. The difference in strength values at $5 \mathrm{~h}$ in the second T6 aging step, and that obtained at $8 \mathrm{~h}$, may be that the incoherent precipitates appearing after $5 \mathrm{~h}$ and disappearing later due to the dissolution of the precipitates and homogenization of the matrix. However, as diffusion/precipitation processes are affected by the aging temperature, the precipitates appear in the aluminum matrix only after an extended aging time [19,21,22]. Regarding the elongation values in Figure 4, it may be seen that the ductility is improved after the multi-temperature treatments of $A_{i}$ cycles. This behavior is to be expected since the corresponding strength values are lower, compared to the standard $\mathrm{T} 6$ aging thermal treatment values. This difference may be related to the formation of coarser precipitates with a lower density in the matrix, and displaying large inter-particle spacing. These changes facilitate dislocation motion and results in softening effects, thus producing increased ductility, as compared to standard T6 single stage aging. The second stage of the aging (T6-aging) is applied to the T7 heat treated alloys ( $\mathrm{B}_{\mathrm{i}}$ Cycles) to improve the strength results; the application of $\mathrm{T} 7 \mathrm{aging}$ step following the T6 step of $A_{i}$ thermal aging cycles leads to achieving an optimum compromise between strength and elongation values, as compared to those results [11-18] obtained by the application of standard T6 and/or T7 thermal aging. In addition, the optimum compromise between hardness, strength, and ductility values obtained in this study aimed at enhancing the crack-failure resistance of the A357 semi solid alloys used in the fabricating of automotive parts as a suspension control arm.

\subsection{Microstructure Characterization}

\subsubsection{SEM Analysis}

Regarding the microstructure characteristics, Figure 5 shows the scanning electron micrographs of A357-T4 semi-solid casting, heat-treated using water quenching media, compared to hot air-direct quenching into an aging medium. These micrographs indicated the positive effects of semi solid-SEED casting technique in addition to the solution heat treatment, $\mathrm{T} 4$, on the microstructure characteristics of A357 aluminum alloys. It may be noted the positive effects of semi-solid casting process and solution heat treatment on the morphology of intermetallic phases, mainly Si and $\mathrm{Fe}$. The $\beta-\mathrm{Al}_{5} \mathrm{FeSi}$ and $\pi-\mathrm{Al}_{8} \mathrm{Mg}_{3} \mathrm{FeSi}_{6}$ iron intermetallic formed in such alloys, were identified using the EDX spectra. 


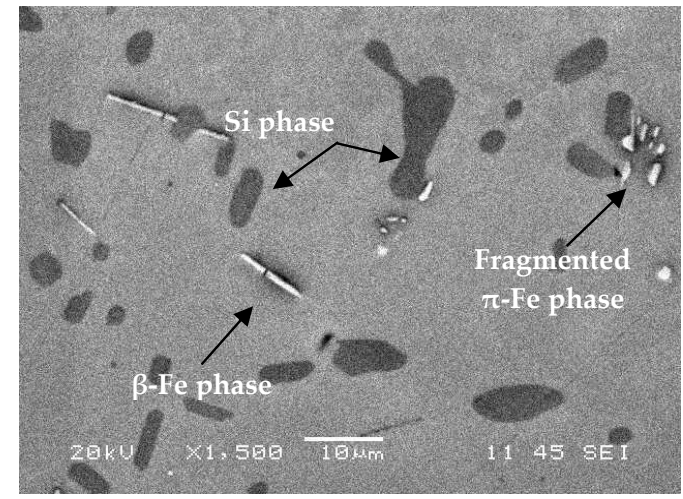

(a) Water Quenching (T4) A357-SSM

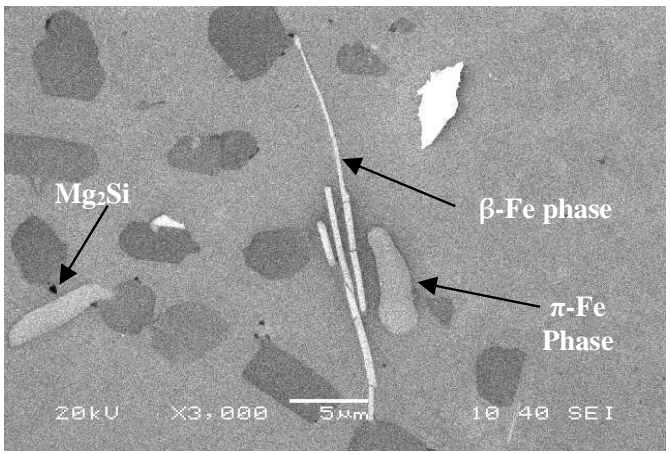

(c) Air Quenching (T4) A357-SSM

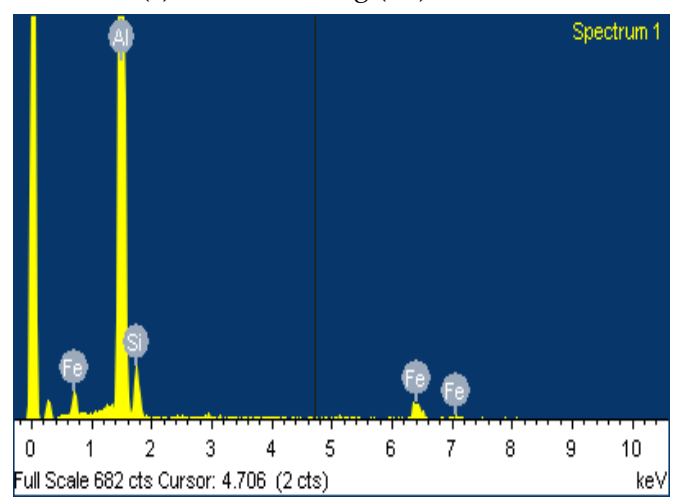

(e) EDX Spectrum ( $\beta$-Fe phase)

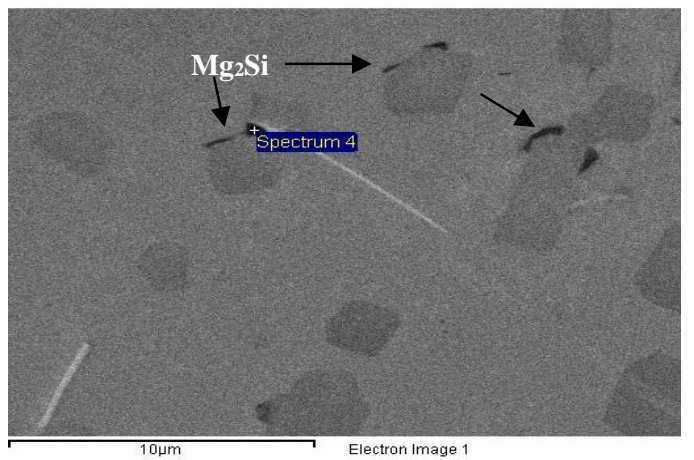

(g) Air Quenching (T4) A357-SSM

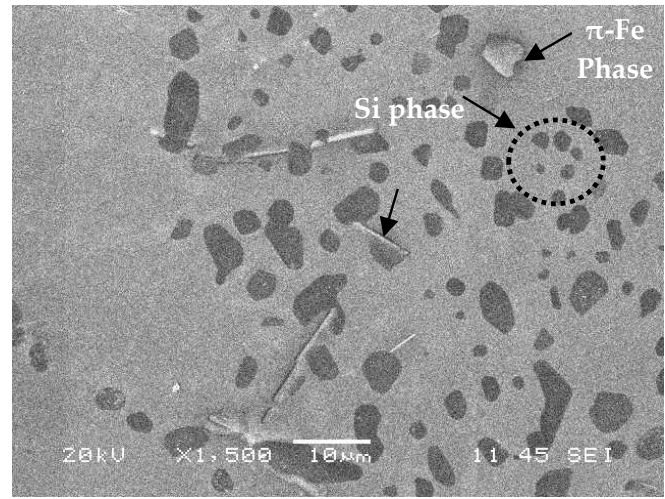

(b) Water Quenching (T4) A357-SSM

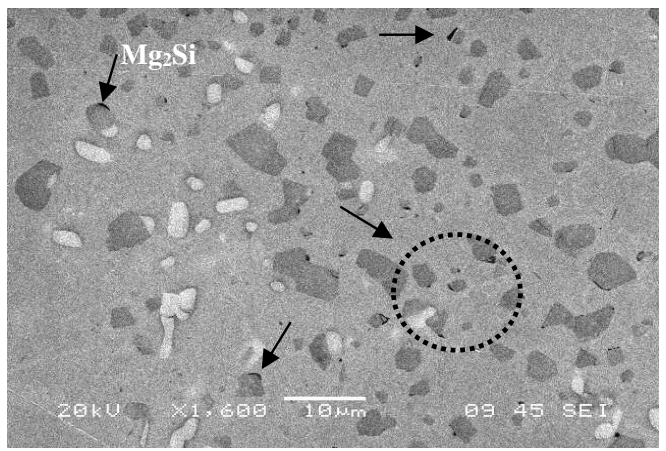

(d) Air Quenching (T4) A357-SSM

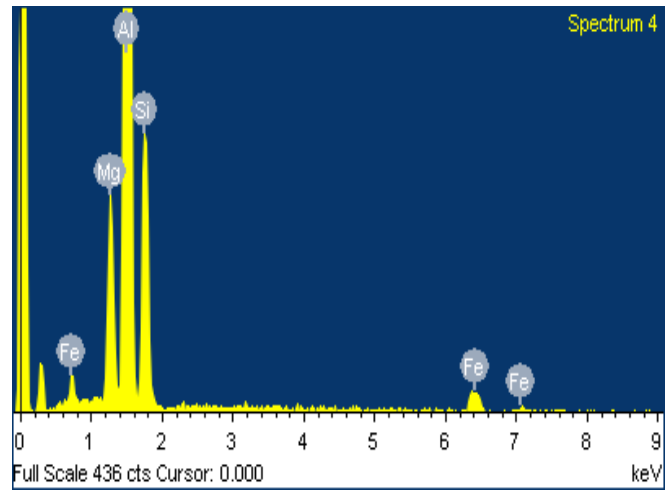

(f) EDX Spectrum ( $\pi$-Fe phase)

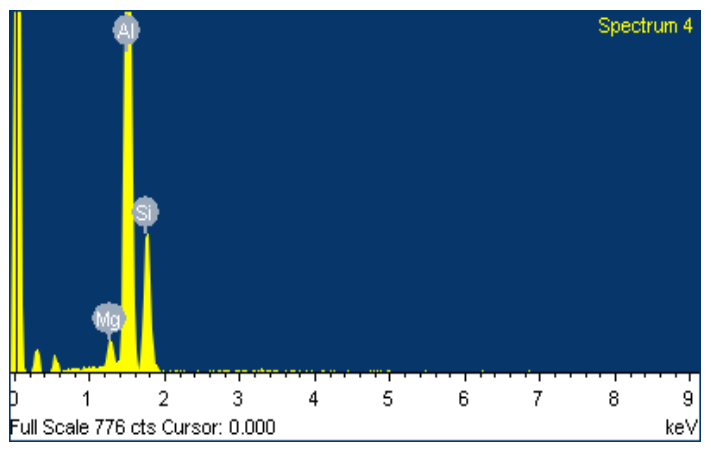

(h) EDX Spectrum ( $\mathrm{Mg}_{2} \mathrm{Si}$ phases)

Figure 5. SEM micrographs of T4 heat treating A357-SSM using water quenching versus direct hot air quenching-aging media. (a) Water Quenching (T4) A357-SSM, (b) Water Quenching (T4) A357-SSM, (c) Air Quenching (T4) A357-SSM, (d) Air Quenching (T4) A357-SSM, (e) EDX Spectrum ( $\beta$-Fe phase), (f) EDX Spectrum ( $\pi$-Fe phase), (g) Air Quenching (T4) A357-SSM, (h) EDX Spectrum ( $\mathrm{Mg}_{2} \mathrm{Si}$ phases). 
Figure $5 \mathrm{a}-\mathrm{d}$ shows the spheroidization of both $\pi$-Fe phases and acicular Si particles. In addition, the fragmentation of $\beta$-Fe phases may be noted, which in turn improves the mechanical characteristics of A357 alloys. These effects on the morphology of such intermetallic phases are related to the positive role of the semi-solid casting process. The detrimental effect of these intermetallic phases is related to iron platelet-like and needle shapes that induce high stress concentrations and constitute a stress raiser resulting in negative effects on the mechanical performance of alloys investigated [23,24]. The solution heat treatment for $6 \mathrm{~h}$ nearly results in the complete dissolution of $\mathrm{Mg}_{2} \mathrm{Si}$ phases and partial fragmentation of Fe-phases that are hardly dissolved in the matrix. The water quenching medium indicated better microstructure characteristics, Figure $5 \mathrm{a}, \mathrm{b}$, compared to those obtained by hot air direct quenching-aging medium, Figure $5 c, d, g$. It may be noted the formation of $\mathrm{Mg}_{2} \mathrm{Si}$ phases out of the matrix after the solution heat treatment procedures by applying T4 thermal aging using hot air direct quenching-aging medium. These phases of $\mathrm{Mg}_{2} \mathrm{Si}$ are identified by using EDX analysis, as shown in Figure $5 \mathrm{~h}$ by EDX spectrum. These formed black $\mathrm{Mg}_{2} \mathrm{Si}$ phases out of the aluminum matrix lead to the decrease of $\mathrm{Mg}$ phases into the matrix, which are necessarily required for the precipitation of Nano strengthening phases of $\mathrm{Mg}_{2} \mathrm{Si}$ after the application of $\mathrm{T} 6$ artificial thermal aging treatments. In addition, these formed phases out of matrix may act as nucleating sites for oxides which have detrimental effects on the mechanical characteristics of the alloys investigated. This was clearly indicated by the decrease of hardness values for the A357 semi solid alloys subjected to multiple thermal aging treatments using hot air as a direct quenching-aging media, as compared to those alloys heat treated using water quenching medium, as shown in Figures 1 and 2. The reduction in hardness values with a reduced quenching rate may be related to the formation of $\mathrm{Mg}_{2} \mathrm{Si}$ phases out of the matrix and to amount of vacancies present. Upon quenching from the solution temperature, vacancies are retained in the $\mathrm{Al}$ matrix. It should be noted that the lower the vacancy concentration, the slower the resultant aging process and the higher the related transformation temperature for GP zone formation and precipitation $[11,15,18]$. It has been investigated, by several studies $[4,8,11,25]$ applied on Al-Si-Mg alloys, that the high cooling rate from water quenching results in the greatest concentration of vacancies; these vacancies act as nucleation sites for precipitates. Conversely, hot air quenching provides the lowest strength values due to the low cooling rate and low heat transfer rate. The air quenching technique has been employed for automobile castings such as cylinder blocks and heads which are fitted with cast iron liners, where the slow air quench is suitable due to the difference in the quench characteristics of iron and aluminium. Several factors affect the feasibility of air quenching, such as airflow, air quench temperature, and casting configuration. However, the use of a hot air quenching system, the materials lose a certain amount of energy on cooling from the solution to the aging temperature inside the furnace resulting in a significant decrease in the mechanical performance due to the low quality of microstructure characteristics.

\subsubsection{TEM Analysis}

Several studies have investigated the precipitation of the $\mathrm{Mg}_{2} \mathrm{Si}$ in Aluminum alloys by transmission electron microscopy (TEM) [10-15]. However, little research work involving TEM study of A357 and Al-Si-Mg, semi solid casting alloys, which have been applied specifically for multiple thermal aging treatments. TEM research may provide information about the crystal structure, size, shape, and distribution of the precipitates that are necessary parameters to understand precipitation hardening. One of the disadvantages of TEM studies is that the volume that can be analyzed per sample is small, around $10^{-20}-10^{-18} \mathrm{~m}^{3}$ [13-15]. The strengthening precipitates formed at specific multiple thermal aging treatments, for A357 semi solid alloys, are shown in Figure 6. 


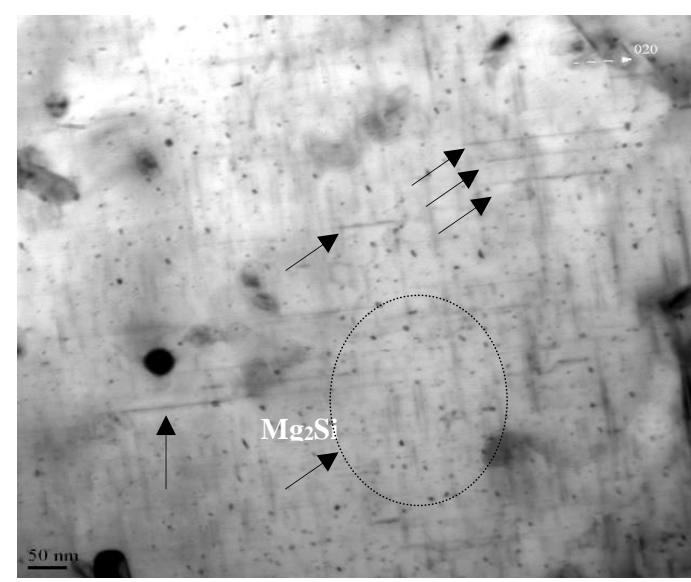

(a) Thermal Aging Cycle, T7/T6 (WB5)

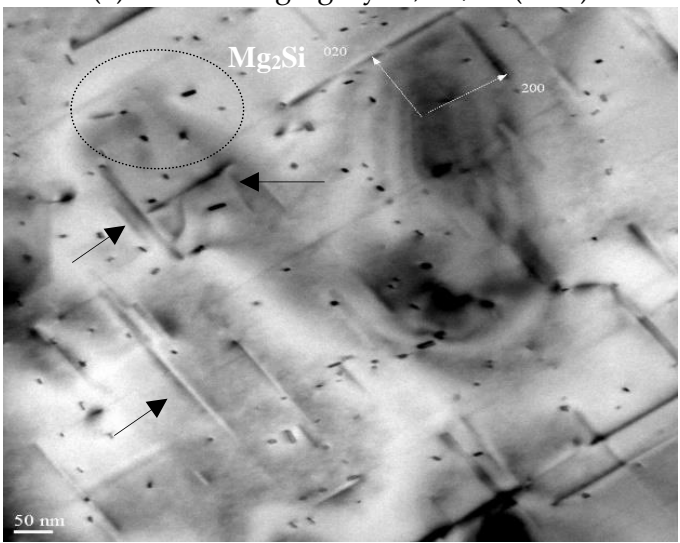

(c) Thermal Aging Cycle, T7/T6 (WB8)

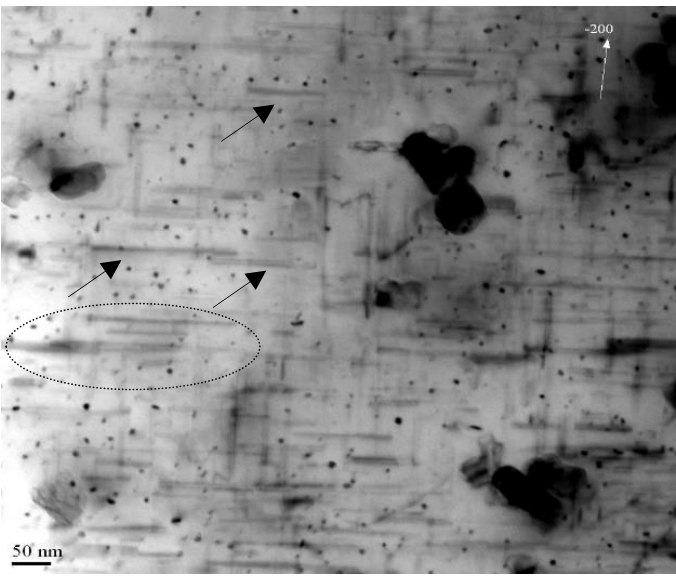

(e) Thermal Aging Cycle, T6/T4/T7 (WC3)

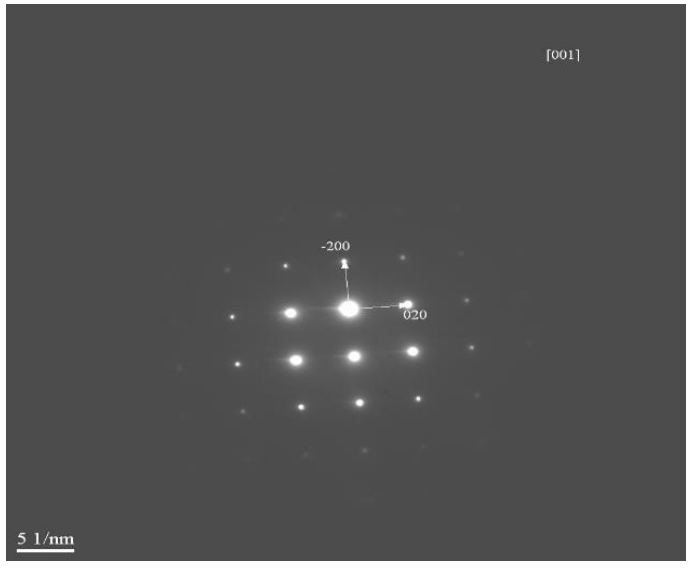

(b) Electron diffraction pattern, direction [001]

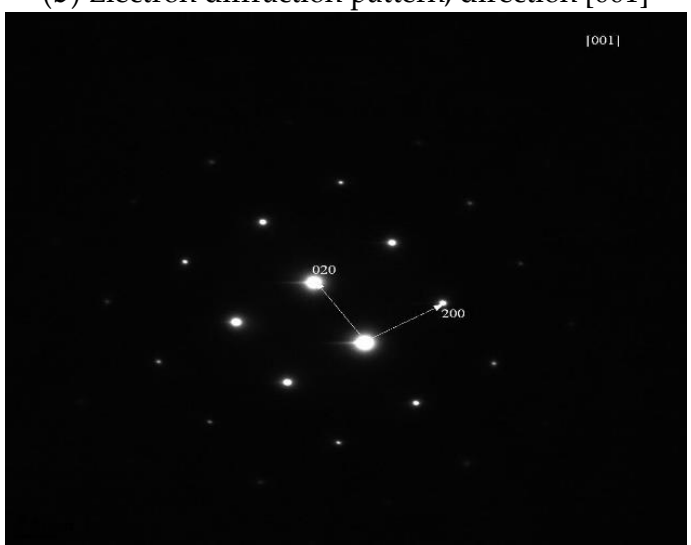

(d) Electron diffraction pattern, direction [001]

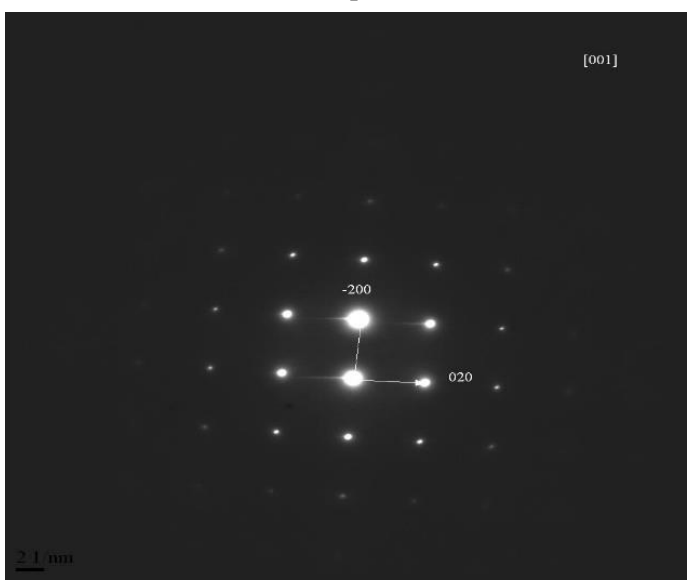

(f) Electron diffraction pattern, direction [001]

Figure 6. TEM micrographs showing the formation of different sizes of $\mathrm{Mg}_{2}$ Si precipitates of A357-SSM heat treating by multiple and interrupted thermal aging cycles. (a) Thermal Aging Cycle, T7/T6 ( $\left.\mathrm{WB}_{5}\right)$, (b) Electron diffraction pattern, direction [001], (c) Thermal Aging Cycle, T7/T6 (WB $)_{8}$, (d) Electron diffraction pattern, direction [001], (e) Thermal Aging Cycle, T6/T4/T7 (WC 3 ), (f) Electron diffraction pattern, direction [001].

The TEM microstructures of aged alloys contain fine precipitates of Nano-sized Mg2Si; these phases were identified by their electron diffraction patterns for miller indices of directions [020] and [200]. The specific multiple thermal aging conditions were selected, for TEM analysis, based on the interesting values of electrical conductivity, micro-hardness and tensile properties to indicate the 
influence of multiple thermal aging treatments on the characteristics of $\mathrm{Mg}_{2} \mathrm{Si}$ strengthening particles. These characteristics include the variable sizes and density of such hardening phases due to the application of multiple and interrupted thermal aging treatments, mainly T4, T6, and T7 tempers. The TEM microstructures of such specific aging cycles contain $\mathrm{Mg}_{2} \mathrm{Si}$ precipitates of different sizes ranging from $10 \mathrm{~nm}$ to $200 \mathrm{~nm}$. The TEM micrograph indicates the presence of two size types, namely $\beta^{\prime \prime}$ and $\beta^{\prime}$, of $\mathrm{Mg}$ and Si phases of a ratio of 2:1 that were picked out from the matrix. The black particles are $\mathrm{Mg}$-Si containing precipitates that denote the presence of $\mathrm{Mg}_{2} \mathrm{Si}$ phase, whereas the dark coarse particles are silicon precipitates formed during the aging procedure in the final stage of phase transformation. The precipitation of silicon in the Al-Si-Mg alloys was reported by References [26,27] where it was observed that silicon precipitates form during the aging cycle in the final stage of the phase transformation process. The microstructures reveal the $\mathrm{Mg}_{2} \mathrm{Si}$ as uniformly distributed phases of spherically-shaped particles (vertical z-direction) and of rod/needle-shaped ones; such spherical $\mathrm{Mg}_{2} \mathrm{Si}$ particles were also observed in other studies $[15,28]$. It was difficult to see, even by TEM, any $\mathrm{Mg}_{2} \mathrm{Si}$ precipitates formed by applying T6 aging cycle of two hours; such short time aging heat treatment produces tiny precipitates of Nano sized particles of $\mathrm{Mg}_{2} \mathrm{Si}$ formed as clusters or as GP zones that explain the highest hardness values after T aging condition. Regarding the aging cycle of T7/T6, the difference in particle sizes clearly implies the formation of two precipitates size types that may be identified mainly as $\beta^{\prime \prime}$ and $\beta^{\prime}$. In addition to the large size of precipitates formed by first step aging T7 cycle, the small size precipitates obtained by second step T6 aging cycle explains the increase in hardness values compared to those formed by T6/T7 aging cycles. Regarding to multiple aging cycles applied in this work, Figure 6 and Table 2 showed that there are two and/or three different sizes of $\mathrm{Mg}_{2} \mathrm{Si}$ for the heat treatment cycle investigated.

Table 2. Average length of the $\mathrm{Mg}_{2} \mathrm{Si}$ precipitates of A357-SSM alloys.

\begin{tabular}{ccc}
\hline Thermal Aging Cycles & \multicolumn{2}{c}{ Average Length, $\mathbf{n m}$} \\
\hline \multirow{2}{*}{$\mathrm{WB}_{5}(\mathrm{~T} 7 / \mathrm{T} 6)$} & $10.5 \pm 1.4 \mathrm{~nm}$ & $46.27 \pm 0.6 \mathrm{~nm}$ \\
& $82.42 \pm 1.7 \mathrm{~nm}$ & $199.12 \pm 1.2 \mathrm{~nm}$ \\
\hline \multirow{2}{*}{$\mathrm{WB}_{8}(\mathrm{~T} 7 / \mathrm{T} 6)$} & $28.1 \pm 2.3 \mathrm{~nm}$ & $56.7 \pm 1.1 \mathrm{~nm}$ \\
& $98.47 \pm 1.8 \mathrm{~nm}$ & $245.21 \pm 2.1 \mathrm{~nm}$ \\
\hline \multirow{2}{*}{$\mathrm{WC}_{3}(\mathrm{~T} 6 / \mathrm{T} 4 / \mathrm{T} 7)$} & $10.32 \pm 1.4 \mathrm{~nm}$ & $32 \pm 1.1 \mathrm{~nm}$ \\
& $80.5 \pm 2.1 \mathrm{~nm}$ & $206.47 \pm 1.9 \mathrm{~nm}$ \\
\hline
\end{tabular}

The size of such precipitates was measured using a software program connected to optical microscopy as indicated by Table 2 . It has been indicated by literatures [10-15,25-28] that the $\mathrm{Mg}_{2} \mathrm{Si}$ precipitates size may range from $10 \mathrm{~nm}$ to $500 \mathrm{~nm}$, mainly $\beta^{\prime \prime} 10-20 \mathrm{~nm}, \beta^{\prime} 145 \mathrm{~nm}$ and $\beta$ more than $500 \mathrm{~nm}$, relating to the thermal aging parameters of different temperatures and times applied for Al-Si-Mg alloys. Regarding the thermal aging cycles of $\mathrm{B}_{5}$ and $\mathrm{B}_{8}$ (T7/T6) conditions, the precipitates size of B8 cycles showed a bigger size (length and thickness) compared to those obtained by B5 condition. This difference is related to the over-aging effect after $8 \mathrm{~h}$ of T6 thermal aging following the $2 \mathrm{~h}$ of T7 step; this may clearly explain the decrease in strength and hardness results when going from $B_{5}$ to $B_{8}$ thermal aging cycles, as shown in Figures 1-3. Regarding $C_{3}$ thermal aging cycles, it was indicated the formation of finer and well distributed precipitates compared to $\mathrm{B}_{5,8}$ thermal aging cycles; this may also explain its highest strength and hardness results. A dense precipitation of Nano-sized $\mathrm{Mg}_{2} \mathrm{Si}$ particles will impede the movement of dislocations through the matrix more effectively, rendering the material stronger; when the precipitates are widely dispersed the dislocations can cross between them. It was observed that there is still a high concentration of needlelike precipitates; this behavior indicates that the under aging stage after the actual over-aging stage would be beneficial to the material. The under aging, carried out at a lower temperature at $150{ }^{\circ} \mathrm{C}$, will cause nucleation of early metastable phases, which in turn will produce a smaller and better distributed stable phase, thereby improving the mechanical properties of the material. 


\section{Conclusions}

1. The hardness results obtained after the T6 continuous aging treatment $\left(\mathrm{WA}_{0}\right)$ of A357SSM alloys are not improved by means of T6/T7 aging (A) cycles. However, the application of T6/T7 aging $\left(\mathrm{WA}_{1}\right)$ cycle and of T7/T6 aging (B) cycles improved the hardness and Tensile strength values compared to $\mathrm{T} 6$ under aging $\left(\mathrm{WA}_{0}\right)$ and $\mathrm{T} 7$ standard over aging $\left(\mathrm{WB}_{0}\right)$ conditions, respectively.

2. The application of multiple aging (B) cycles (T7/T6) indicates a continuous increase in the hardness and strength values with increasing the time of second thermal aging step till five, followed by a decrease in its mechanical values (over-aging). The application of Interrupted aging cycles $\left(\mathrm{WC}_{3}\right)$ leads to increasing the strength values to be higher than those obtained by most of the applied thermal treatment cycles.

3. The two steps thermal aging $\left(\mathrm{WA}_{1-8}\right)$ cycles $(\mathrm{T} 6 / \mathrm{T} 7)$ indicated an improvement of ductility values by increasing the time of the second step of thermal aging.

4. The electrical conductivity values increase continuously with increasing aging temperature by applying T7 aging directly after T6 condition (T6/T7). In addition, there is a reverse relationship between electrical conductivity and hardness values as relating to different aging cycles applied in this study.

5. The water quenching of A357 SSM indicated higher hardness values compared to direct Air quenching-aging alloys. The air quenching results in the formation of hardening $\mathrm{Mg}_{2} \mathrm{Si}$ phases out of Aluminum matrix-solid solution (as shown in SEM microstructures) resulting in a negative effect on the mechanical properties of Alloys investigated.

6. Regarding to the TEM observations, the application of interrupted aging $\left(\mathrm{WC}_{3}\right)$ cycles and two step T7/T6 aging $\left(\mathrm{WB}_{5}\right.$ and $\left.\mathrm{WB}_{8}\right)$ cycles leads to formation of different precipitate sizes that are mostly related to $\beta^{\prime \prime}$ and $\beta^{\prime}$ phases. The shorter/finer precipitates formed by applying T6 second aging step, alongside the coarse precipitates size formed by T7 first step aging that resulted in a significant increase in the hardness values compared to the $\mathrm{T} 7$ single step aging cycle $\left(\mathrm{WB}_{0}\right)$.

Author Contributions: K.A.R., M.B, and X.G.C. conceived and designed the experiments; K.A.R. performed the experiments; K.A.R. analyzed the data; K.A.R. wrote the paper.

Funding: This research received no external funding.

Acknowledgments: Financial and in-kind support received from the REGAL Aluminum Research Group and the Natural Sciences and Engineering Research Council of Canada (NSERC) through the CURAL lab-University Research Center at the University of Quebec at Chicoutimi (UQAC), is hereby gratefully acknowledged. The authors would also like to thank Zhan Zhang (UQAC) and Mohamed Attia (UQAC) for their assistance in the experiments.

Conflicts of Interest: The authors declare no conflict of interest.

\section{References}

1. Rosso, M. The Influence of Casting Process on Quality and Performances on Al Based Automotive Components. In Proceedings of the 13th International Scientific Conference on Achievements in Mechanical and Materials Engineering, Gliwice-Wista, Poland, 16-19 May 2005; pp. 547-550.

2. Langlais, J.; Lemieux, A. The SEED technology for semi-solid processing of aluminum alloys: A metallurgical and process overview. Solid State Phenom. 2006, 116-117, 472-477. [CrossRef]

3. Davis, J.R. ASM Specialty Handbook: Aluminum and Aluminum Alloys; ASM International: Materials Park, $\mathrm{OH}$, USA, 1993.

4. Askeland, D.R.; Phule, P.P. The Science and Engineering of Materials, 4th ed.; Thomson Brooks: Pacific Grove, CA, USA, 2003; pp. 366, 373, 374.

5. Fridlyander, I.N.; Sister, V.G.; Grushko, O.E.; Berstenev, V.V.; Sheveleva, L.M.; Ivanova, L.A. Aluminum alloys: Promising materials in the automotive industry. Met. Sci. Heat Treat. 2002, 44, 365-370. [CrossRef]

6. Wang, Q.G.; Davidson, C.J. Solidification and precipitation behaviour of Al-Si-Mg casting alloys. J. Mater. Sci. 2001, 36, 739-750. [CrossRef] 
7. Martin, J.W. Precipitation Hardening; Butterworth-Heinemann: Oxford, UK, 1998; p. 215.

8. Zhang, D.L.; Zheng, L.H.; StJohn, D.H. Effect of a short solution treatment time on microstructure and mechanical properties of modified Al-7wt.\% Si-0.3 wt.\% Mg alloy. J. Light Met. 2002, 2, 27-36. [CrossRef]

9. Li, B.; Wang, H.W.; Jie, J.C.; Wei, Z.J. Effects of yttrium and heat treatment on the microstructure and tensile properties of Al-7.5 Si-0.5 Mg alloy. Mater. Des. 2011, 32, 1617-1622. [CrossRef]

10. Shivkumar, S.; Keller, C.; Apelian, D. Aging behavior in cast Al-Si-Mg alloys. AFS Trans. 1990, 98, 905-911.

11. Abdulwahab, M.; Madugu, I.A.; Yaro, S.A. Effects of temper conditions and step-quenching-ageing on the hardness characteristics and yield strength of A356.0-type Al-Si-Mg alloy. Silicon 2012, 4, 137-143. [CrossRef]

12. Li, R.X.; Li, R.D.; Zhao, Y.H.; He, L.Z.; Li, C.X.; Guan, H.R.; Hu, Z.Q. Age-hardening behavior of cast Al-Si base alloy. Mater. Lett. 2004, 58, 2096-2101. [CrossRef]

13. Andersen, S.J.; Marioara, C.D.; Vissers, R.; Frøseth, A.; Zandbergen, H.W. The structural relation between precipitates in Al-Mg-Si alloys, the Al-matrix and diamond silicon, with emphasis on the trigonal phase U1-MgAl ${ }_{2} \mathrm{Si}_{2}$. Mater. Sci. Eng. A 2007, 444, 157-169. [CrossRef]

14. Matsumoto, K.; Komatsu, S.-y.; Ikeda, M.; Verlinden, B.; Ratchev, P. Quantification of volume fraction of precipitates in an aged Al-1.0 mass \% $\mathrm{Mg}_{2} \mathrm{Si}$ alloy. Mater. Trans. 2000, 41, 1275-1281. [CrossRef]

15. Ding, L.P.; Jia, Z.H.; Nie, J.F.; Weng, Y.Y.; Cao, L.F.; Chen, H.W.; Wu, X.Z.; Liu, Q. The structural and compositional evolution of precipitates in Al-Mg-Si-Cu alloy. Acta Mater. 2018, 145, 437-450. [CrossRef]

16. Salazar-Guapuriche, M.A.; Zhao, Y.Y.; Pitman, A.; Greene, A. Correlation of strength with hardness and electrical conductivity for aluminium alloy 7010. Mater. Sci. Forum. 2006, 519, 853-858. [CrossRef]

17. Ravi, C.; Wolverton, C. First-principles study of crystal structure and stability of Al-Mg-Si-(Cu) precipitates. Acta Mater. 2004, 52, 4213-4227. [CrossRef]

18. Zhang, J.Y.; Ma, M.Y.; Shen, F.H.; Yi, D.Q.; Wang, B. Influence of deformation and annealing on electrical conductivity, mechanical properties and texture of Al-Mg-Si alloy cables. Mater. Sci. Eng. A 2018, 710, $27-37$. [CrossRef]

19. Ferragut, R.; Somoza, A.; Torriani, I. Pre-precipitation study in the $7012 \mathrm{Al}-\mathrm{Zn}-\mathrm{Mg}-\mathrm{Cu}$ alloy by electrical resistivity. Mater. Sci. Eng. A 2002, 334, 1-5. [CrossRef]

20. Mavlyutov, A.M.; Bondarenko, A.S.; Murashkin, M.Y.; Boltynjuk, E.V.; Valiev, R.Z.; Orlova, T.S. Effect of annealing on microhardness and electrical resistivity of nanostructured SPD aluminium. J. Alloys Compd. 2017, 698, 539-546. [CrossRef]

21. Abdulwahab, M.; Madugu, I.A.; Yaro, S.A.; Hassan, S.B. Effects of multiple-step thermal ageing treatment on the hardness characteristics of A356. 0-type Al-Si-Mg alloy. Mater. Des. 2011, 32, 1159-1166. [CrossRef]

22. Tiryakioğlu, M.; Campbell, J.; Staley, J.T. Hardness-strength relationships in cast Al-Si-Mg alloys. Mater. Sci. Forum. 2000, 331-337, 295-300. [CrossRef]

23. Ragab, Kh.A.; Bouaicha, A.; Bouazara, M. Optimization of Casting Design Parameters on Fabrication of Reliable Semi-Solid Aluminum Suspension Control Arm. J. Mater. Eng. Perform. 2017, 26, 4450-4461. [CrossRef]

24. Ragab, K.A.; Bouazara, M.; Bouaicha, A.; Allaoui, O. Microstructural and mechanical features of aluminium semi-solid alloys made by rheocasting technique. Mater. Sci. Technol. 2017, 33, 646-655. [CrossRef]

25. Abubakre, O.K.; Mamaki, U.P.; Muriana, R.A. Investigation of the quenching properties of selected media on 6061 aluminum alloy. J. Min. Mater. Charact. Eng. 2009, 8, 303-315. [CrossRef]

26. Gupta, A.K.; Lloyd, D.J. Precipitation hardening in Al-Mg-Si alloys with and without excess Si. Mater. Sci. Eng. A 2001, 316, 11-17. [CrossRef]

27. Murayama, M.; Hono, K. Pre-precipitate clusters and precipitation processes in Al-Mg-Si alloys. Acta Mater. 1999, 47, 1537-1548. [CrossRef]

28. Ding, L.P.; Jia, Z.H.; Zhang, Z.Q.; Sanders, R.E.; Liu, Q.; Yang, G. The natural aging and precipitation hardening behavior of Al-Mg-Si-Cu alloys with different $\mathrm{Mg} / \mathrm{Si}$ ratios and $\mathrm{Cu}$ additions. Mater. Sci. Eng. A 2015, 627, 119-126. [CrossRef]

(c) 2018 by the authors. Licensee MDPI, Basel, Switzerland. This article is an open access article distributed under the terms and conditions of the Creative Commons Attribution (CC BY) license (http:/ / creativecommons.org/licenses/by/4.0/). 